\title{
A CONSTRUÇÃO DO OBJETO DE ENSINO SEMINÁRIO SOB O PONTO DE VISTA DOS GESTOS DIDÁTICOS
}

\author{
Mariza Perobelli* \\ Universidade Tecnológica Federal do Paraná \\ Departamento Acadêmico de Ensino \\ Ponta Grossa, PR, Brasil
}

\begin{abstract}
Resumo: Este artigo examina a maneira como o objeto de ensino seminário é transformado em objeto ensinado pelo viés dos gestos didáticos, entendidos como instrumentos de linguagem a serviço do processo de ensino-aprendizagem. As reflexões fundamentam-se nos pressupostos teórico-metodológicos do Interacionismo Sociodiscursivo (ISD) e aportes teóricos dele decorrentes. Os dados da pesquisa foram gerados a partir da implementação de uma sequência de ensino, em uma turma de $8^{\circ}$ ano do ensino fundamental II, por uma professora de escola pública estadual da cidade de Dourados, Mato Grosso do Sul. A análise dos dados ampliou a noção de gestos didáticos e demonstrou a relevância desses movimentos linguageiros em práxis envolvendo gêneros textuais orais. Conclui pela necessidade de um acompanhamento pedagógico focalizado nas práticas didáticas docentes relacionadas aos gêneros textuais orais formais públicos, em âmbito de formação inicial e continuada, sob o ponto de vista desses gestos didáticos.
\end{abstract}

Palavras-chave: Gêneros textuais orais. Trabalho docente. Gestos didáticos.

1 INTRODUÇÃO

Neste artigo, um recorte de nossa dissertação de mestrado ${ }^{1}$, apresentamos resultados parciais provenientes da análise de dados gerados a partir da implementação de uma sequência de ensino, em uma turma de $8^{\circ}$ ano do ensino fundamental II, por uma professora de escola da rede pública estadual da cidade de Dourados-MS. A sequência de ensino, doravante SE, voltava-se ao gênero textual oral formal público seminário, um dos gêneros textuais de divulgação científica indicados nos Parâmetros Curriculares Nacionais (BRASIL, 1998), para o trabalho com a linguagem oral, cujo domínio é fundamental para a efetiva participação social. Teve como objetivo o estudo desse gênero textual e, concomitantemente, a produção de uma exposição ${ }^{2}$ que, ao final do trabalho, seria apresentada aos colegas da turma.

\footnotetext{
${ }^{*}$ Mestre em Letras pela Universidade Federal da Grande Dourados (UFGD). Professora do Instituto Federal Farroupilha (IFFar) em exercício provisório na UTFPR, atuando em cursos de graduação. ORCID: <https://orcid.org/0000-0003-2086-2292>. E-mail: mperobelli@yahoo.com.br.

${ }^{1}$ Dissertação defendida no ano de 2017, sob o título O gênero seminário em educação: gestos e dispositivos didáticos, orientada pelo prof. Dr. Adair Vieira Gonçalves.

${ }^{2}$ Dolz et al. (2011) afirmam, em seu artigo A exposição oral (2011, p. 183-211), que o termo seminário é frequentemente utilizado nas escolas quando se trata de exposição oral. Assim, em consonância com os autores, usamos também o termo exposição neste trabalho.
} 
No âmbito escolar, locus de nossa pesquisa, o seminário é frequentemente proposto ou como meio para o ensino de conteúdos, ou para a verificação dos conhecimentos dos discentes. Não há um trabalho sistemático que oriente os alunos, por exemplo, para a pesquisa do tema, para a organização da apresentação, para a postura e gestos adequados a serem observados na apresentação, entre outros aspectos. Trata-se da realidade do contexto brasileiro, conforme já observado em trabalhos como de Lopes (2010) e Freitas (2016). Isso é o que também afirmam Dolz et al. (2011, p. 184) ao se referirem ao contexto francófono:

[...] a exposição [o seminário] vem de uma longa tradição e é constantemente praticada, muitíssimas vezes isso se dá sem que um verdadeiro trabalho didático tenha sido efetuado, sem que a construção da linguagem expositiva seja objeto de atividade em sala de aula, sem que estratégias concretas de intervenção e procedimentos explícitos de avaliação sejam adotados.

Sob essa perspectiva, propusemo-nos a examinar a transposição didática interna ${ }^{3}$ do objeto de ensino seminário em contexto escolar, articulando três pontos de vista: o do objeto de ensino, o dos gestos didáticos (fundadores e específicos) mobilizados pelo docente e o dos dispositivos didáticos utilizados por ele. As reflexões fundamentam-se em pressupostos teórico-metodológicos do Interacionismo Sociodiscursivo, doravante ISD, bem como em aportes teóricos dele decorrentes. Para tal, tomamos como base textos de pesquisadores do Grupo de Genebra ${ }^{4}$, tais como Aeby-Daghé e Dolz (2008), Schneuwly (2009a, 2009b), Schneuwly, Dolz et al. (2011); e de pesquisadores brasileiros, tais como Nascimento (2011a, 2011b, 2012, 2016), Barros $(2012,2013)$, Oliveira (2012, 2013).

Optamos, no trabalho, por um gênero textual da modalidade oral por entendermos que há a prevalência de pesquisas voltadas para a tradição escrita, e o direcionamento é o de valorização dos gêneros textuais orais formais públicos como objeto de ensino e não como objeto de aprendizagem acessório da escrita, bem como a presença deles no ensino fundamental II, num trabalho didático-pedagógico. Soma-se a isso a possibilidade desafiadora de estudar uma abordagem incipiente na área de Linguística Aplicada, os gestos didáticos (fundadores e específicos) mobilizados pelo docente na transposição didática interna do objeto de ensino seminário.

É sobre os gestos didáticos (fundadores e específicos) mobilizados pelo docente para a construção do objeto ensinado que voltamos o olhar neste texto. O objetivo é

\footnotetext{
${ }^{3}$ De acordo com Machado (2009), para o ISD a concepção de transposição didática é entendida como transformações que sofridas pelos saberes científicos quando se pretende ensiná-los. Nascimento e Brun (2016, no prelo) identificam três níveis nesse processo: o dos sistemas educacionais, o dos sistemas de ensino e o dos sistemas didáticos. Nesse último nível, segundo essas autoras, a transposição didática ocorre em dois momentos: um externo, quando o docente seleciona os objetos de ensino a partir dos saberes de referência; e um interno, alvo de nossa investigação, quando ele transforma esses objetos de ensino em objetos ensinados, por meio de ferramentas/instrumentos de ensino e de gestos didáticos.

${ }^{4}$ Grupo de pesquisadores da chamada "Escola de Genebra", pertencente ao Departamento de Didática de Línguas da Faculdade de Psicologia e Ciências da Educação (FAPSE) da Universidade de Genebra (UNIGE) que dedica suas pesquisas tanto à constituição do ISD quanto a sua aplicação ao ensino de francês como língua materna.
} 
descrever e analisar esses gestos na transposição didática interna de objeto de ensino seminário. Para tal, sintetizamos algumas considerações acerca da noção de gestos didáticos e tratamos do objeto de ensino alvo da sequência de ensino, o gênero textual oral formal público seminário; na sequência, apresentamos parte da análise da pesquisa realizada, para ilustrar a fundamentação teórica, e evidenciamos os dados emergentes da sequência de ensino.

\section{A NOÇÃO DE GESTOS DIDÁTICOS}

A noção de gestos didáticos, doravante GD, emerge da necessidade de reconhecer o ato de ensinar como uma profissão e oferece aporte teórico-metodológico para observar os docentes em seu agir didático, pelo viés das interações linguageiras, em um cenário em que esses gestos atuam como instrumentos mediadores da atividade de ensinoaprendizagem. Procura-se, assim, equiparar o docente a outros profissionais quando da realização de suas tarefas, deixando de ver o trabalho do ensino apenas como mera transmissão de conhecimento, não circunscrita apenas à sala de aula e às relações com os discentes, mas como uma atividade regulada (AMIGUES, 2004), ou seja, um trabalho como qualquer outro.

Esses gestos têm origem na noção de gestos profissionais. Nessa primeira concepção, dizem respeito aos gestos do trabalhador professor em seu métier, reservandose a segunda concepção aos gestos dos professores de determinado componente curricular ao didatizar determinado objeto de ensino (MESSIAS; DOLZ, 2015). Esses autores destacam ainda que os professores, no processo de ensino-aprendizagem, objetivando desenvolver as capacidades dos alunos, promovem intervenções didáticas, ou GD, que "[...] constituem o seu agir na realização da tarefa central de seu métier" (MESSIAS; DOLZ, 2015, p. 50). Trata-se, então, para os autores, de um conjunto de movimentos cuja finalidade é pedagógica.

Em relação a esses GD, esses autores destacam que Schneuwly (2009), retomando o trabalho de Aeby-Daghé e Dolz (2008), elenca quatro gestos fundamentais: o de implementação do dispositivo didático, o de criação da memória didática, o de regulação e o de institucionalização, aos quais se ligam os gestos de presentificação e elementarização ou focalização, sendo que para Schneuwly (2009) os dois últimos integram o gesto de implementação do dispositivo didático.

Segundo Nascimento (2011a), os GD visam sempre à aprendizagem do estudante. Ou seja, por meio desses gestos o professor apresenta o objeto de ensino aos alunos. Por exemplo, aos propor uma atividade escolar, focalizando uma ou mais dimensões do objeto, ele pode escrever uma instrução no quadro de giz, apresentá-la(s) no material fotocopiado ou fazer isso oralmente. Esses movimentos, para Nascimento e Brun (2016, no prelo), "[...] ajudam a compreender o modo como os objetos de ensino são regulados por eles e, ao mesmo tempo, permitem descrever como o docente seleciona os conteúdos para presentificá-los nesses objetos".

Para Nascimento (2011a, p. 423), trata-se de “[...] movimentos discursivos e pragmáticos observáveis no desenvolvimento das atividades didáticas [...]" que o docente desenvolve nas atividades inerentes aos diferentes componentes curriculares em seu trabalho na sala de aula, durante o processo de ensino-aprendizagem, e que potencializam 
suas ações. A autora corrobora as palavras de Aeby-Daghé e Dolz (2008, p. 83), para quem os GD correspondem a "[...] movimentos observáveis no contexto de trabalho que contribuem para a realização de atividades visando a uma aprendizagem”. Na definição da autora, a noção de GD refere-se a movimentos tanto discursivos quanto pragmáticos, ou seja, os GD constituem movimentos tanto verbais - linguageiros - quanto não verbais - posturas.

Já Oliveira (2012, p. 6), retomando Jorro e a sua noção de gestos (1998), destaca que essa autora não concebe compreendê-los apenas em termos de gesticulações ou movimentos "[...] mas também compreendê-los como uma dimensão simbólica e interpretativa, uma intencionalidade e um efeito estruturador dentro do trabalho do professor". Ou seja, a noção de gestos deve ir além do movimento corporal, paralinguístico, abarcando também uma perspectiva interpretativa, uma vez que envolvem movimentos linguageiros ${ }^{5}$.

Nascimento (2012, p. 28, grifos da autora), em relação aos GD, afirma que

\begin{abstract}
são resultantes da dimensão subjetiva que envolve conhecimentos e experiências individuais e sociais constituídas nas relações do e no trabalho, mas estão impregnados da história de vida e das experiências vivenciadas na vida pessoal e profissional. Professores apresentam estilos peculiares para o agir em sala de aula: uns têm a capacidade maior ou menor de tornar dinâmica e envolvente a interação com os alunos e entre os alunos, de prender a atenção da classe, de resolver crises, criar situações de humor, aliviar tensões, brincar com os alunos, encenar situações, etc. Ao mesmo tempo, conseguem controlar a situação e retornar ao gênero da atividade dando-lhe contornos próprios.
\end{abstract}

De acordo com Nascimento, podemos falar em duas categorias de GD: os fundadores e os específicos. A primeira categoria, os gestos fundadores, engloba "os meios pelos quais um objeto (de ensino e aprendizagem) é presentificado em uma sequência de atividades didáticas" (NASCIMENTO, 2011a, p. 426, grifos da autora). Conforme essa autora, eles

\begin{abstract}
presentificam e topicalizam um conteúdo em sala de aula, fazendo emergir um sistema de gestos didáticos no interior do sistema didático, tais como: 1) a forma como o professor inicia a topicalização de um objeto novo; 2) a maneira como formula e regula as tarefas em sala de aula; 3 ) a mediação por instrumentos para regular as atividades em sala; 4) a maneira como institucionaliza o conteúdo. (NASCIMENTO, 2011a, p. 434, grifos da autora).
\end{abstract}

Ou seja, trata-se de GD comuns entre professores ao executarem seu ofício, uma espécie de padrão a ser seguido, correspondendo a práticas já consolidadas no espaço escolar pelos pares no seu métier. Com base nessas regras estabelecidas, o professor os mobiliza, tendo em vista fazer os alunos compreenderem um determinado objeto de ensino.

\footnotetext{
${ }^{5}$ Em nossa pesquisa, tratamos apenas dos movimentos didáticos/linguageiros, ou ações de linguagem, que podem ser observados no diálogo estabelecido pelo professor em seu trabalho e que visam "aos saberes, aos modos de pensamento e de agir que, em seu conjunto, contribuem para o desenvolvimento global do aprendiz no processo de ensino-aprendizagem" (MESSIAS; DOLZ, 2015, p. 52).
} 
Barros (2012), fundamentada nas pesquisas de Aeby-Daghé e Dolz (2008) realizadas em contexto suíço, propõe a seguinte divisão, que tomaremos como base neste trabalho: a presentificação, o apontamento/elementarização, a formulação de tarefas, a criação de dispositivos didáticos, a utilização da memória, a regulação e a institucionalização.

O GD de presentificação, para Barros (2012, p. 111-112, grifos e comentários da autora), com base nas pesquisas de Aeby-Daghé e Dolz (2008), “[...] tem por finalidade apresentar aos alunos um objeto social de referência, no suporte (MARCUSCHI, 2008) adequado, que passará por um processo de didatização [...]”. Ou seja, a presentificação equivale a apresentar aos alunos os objetos de ensino a serem apreendidos através de dispositivos didáticos. A análise desse gesto permite identificar os aspectos gerais ou as dimensões particulares do objeto de ensino e verificar os gestos específicos por meio da intervenção didática do professor.

O GD de apontamento/elementarização centra-se em uma, ou mais, dimensão(s) ensinável(s) do objeto de ensino, ou seja, consiste em decompor essa(s) dimensão(s) ensinável(s) bem como em colocá-la(s) em destaque. Esse gesto, que dá seguimento ao gesto de presentificação, está também pressuposto, pois uma SE coloca em evidência certos conhecimentos em detrimento de outros para explorar o objeto de ensino. Ou seja, o professor aponta/elementariza, por exemplo, o uso de recursos/suportes na apresentação de seminários, ou os meios não verbais a serem considerados nela e não as técnicas de elaboração e produção do conteúdo das apresentações.

O GD de formulação de tarefas, que se concretiza através de comandos de trabalho (NASCIMENTO, 2011b), representa a porta de entrada dos dispositivos didáticos (BARROS, 2012). Através desses comandos de trabalho, o professor presentifica um objeto de ensino.

O GD de criação de dispositivos didáticos diz respeito ao conjunto de movimentos empreendidos pelo professor para apresentar o objeto de ensino. Pressupõe a mobilização pelo professor de ferramentas/instrumentos materiais e/ou linguageiros tendo em vista apresentar aos alunos o objeto de ensino e que asseguram a interação deles com esse objeto.

O GD de utilização da memória equivale às intervenções realizadas pelo professor para mobilizar conhecimentos ensinados em aula(s) anterior(res), tendo em vista contribuir para a compreensão do que abordará na SE, dando coesão e coerência ao processo de ensino-aprendizagem. Trata-se de um GD que relaciona o que foi visto com o que é visto e o que será visto ${ }^{6}$ (SCHNEUWLY, 2009a), para que os diferentes elementos do objeto de ensino possam constituir um todo.

O GD de regulação diz respeito às intervenções feitas pelo professor para colher informações sobre os efeitos da implementação do dispositivo didático no processo de transposição didática interna do objeto. Envolve, portanto, a criação de meios, pelo professor, para identificar os obstáculos - ou as apropriações - dos alunos no processo de construção do objeto. Um exemplo, no caso da SE alvo de nossa investigação, seria a proposição da produção inicial, ou seja, a apresentação de um seminário em que os alunos

6 “[...] été vu, est vu et va être vu [...]” (SCHNEUWLY, 2009a, p. 40). 
revelariam as representações que têm do gênero textual. Barros (2012, p. 111-112, grifos e comentários da autora) com base nas pesquisas de Aeby-Daghé e Dolz (2008), destaca que o GD de regulação

[...] inclui dois fenômenos intrinsecamente relacionados: as regulações internas $e$ as regulações locais. As regulações internas, centradas nas estratégias para obter as informações sobre o estado dos conhecimentos dos alunos (processo diagnóstico), podem estar no início, durante ou no fim de uma atividade didática [...]. As regulações locais operam durante as atividades didáticas, em uma discussão com os alunos ou no decorrer de uma tarefa. A avaliação é considerada um gesto didático específico de regulação.

O GD de institucionalização, para Schneuwly (2009a), tendo como base Brousseau (1998) resulta de um duplo conhecimento: da parte do professor, reconhecer a aprendizagem do aluno; e deste, reconhecer o objeto do conhecimento. Para Oliveira (2012, p. 8), tal gesto corresponde a "[...] uma generalização das informações sobre o objeto [...]". Trata-se de uma generalização que envolve a apresentação de informações sobre o objeto de ensino e que coloca em evidência os novos aspectos desse objeto que os alunos devem aprender.

Trata-se, enfim, de gestos observáveis no processo de transposição didática interna, em qualquer componente curricular, independentemente do objeto de ensino, que podem ser mais bem visualizados na Figura 1.

\section{Figura 1 - Esquema dos gestos didáticos fundadores}

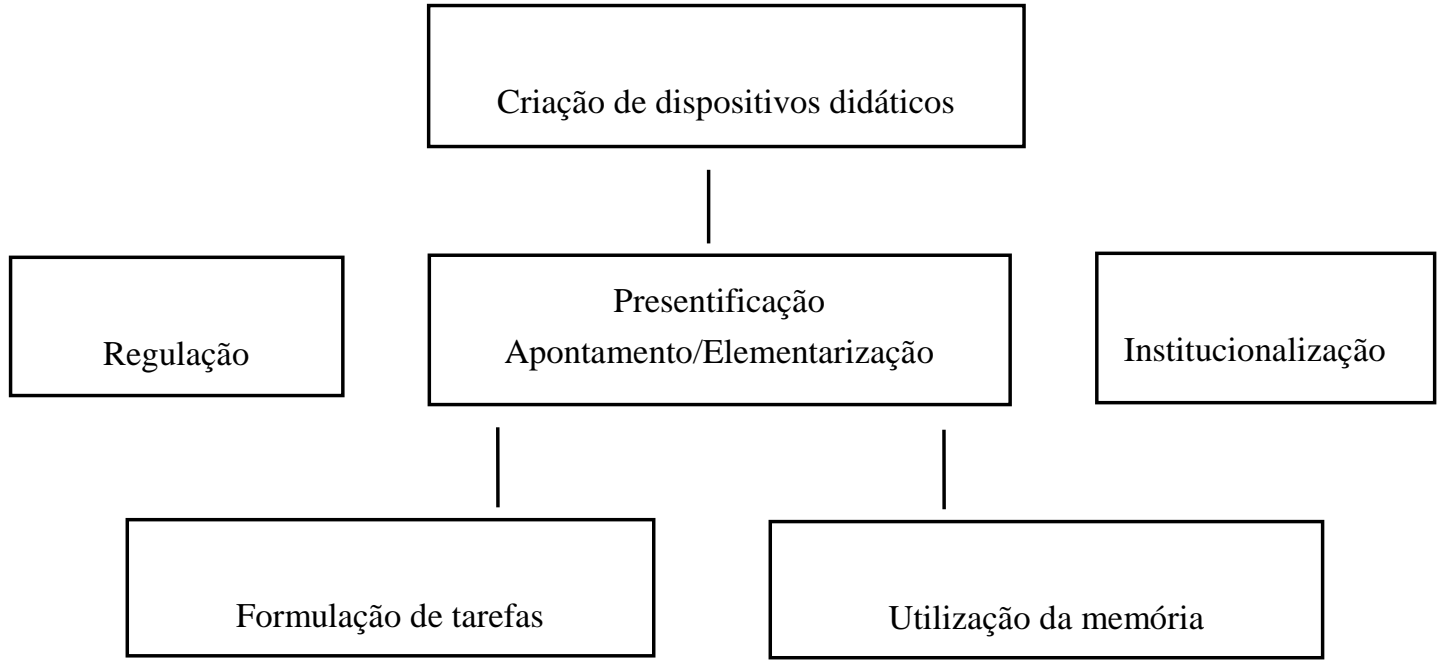

Fonte: elaborado pela autora com base em Aeby-Daghé e Dolz (2008, p. 86).

Na figura 1, visualizamos, ao centro, os GD fundadores considerados por AebyDaghé e Dolz (2008) ponto de partida do processo de transposição didática interna. Por meio deles, apresenta-se o objeto de ensino e delimitam-se suas dimensões ensináveis. A partir deles, o docente mobiliza os demais GD fundadores, de forma a transformar o objeto de ensino em objeto ensinado. 
Já a segunda categoria, os GD específicos, engloba os gestos que "[...] recortam, delimitam, mostram, decompõem o objeto e se ajustam às necessidades dos aprendizes, podendo ser flagrados em diferentes momentos da aula [...]" (NASCIMENTO, 2011a, p. 433). Trata-se dos GD específicos que emergem de acordo com a situação no contexto de sala de aula, durante a atividade do professor ao didatizar um determinado objeto de ensino em determinado componente curricular.

A autora afirma ainda que os GD específicos dizem respeito aos procedimentos singulares de abordar determinado objeto de ensino e que professores experientes descrevem-nos como "ações intuitivas" que resultam de sua experiência profissional. Entretanto, acrescenta que dependem também de conhecerem o conteúdo de suas crenças a respeito de ensino e aprendizagem, da sua capacidade para mobilização de recursos e de proposição de tarefas tendo em vista a aprendizagem dos alunos, entre outros. Os GD específicos representam, então, o tom próprio, o modo sui generis do professor no exercício de seu métier e colaboram na compreensão de como se processa a transformação de um objeto de ensino em objeto ensinado, no nível da transposição didática interna.

\section{O OBJETO DE ENSINO SEMINÁRIO}

Schneuwly (2011, p. 11) ressalta que o trabalho que contemple como objeto de ensino os gêneros textuais orais formais públicos "[...] pode dar acesso ao aluno a uma gama de atividades de linguagem e, assim, desenvolver capacidades de linguagem diversas [...]". Ou seja, diante das inúmeras situações orais formais, um trabalho sistematizado com esses gêneros oportunizará ao estudante vivenciar, em sala de aula, situações de uso da modalidade oral que vivenciará fora do contex to escolar.

Cabe, então, à escola subsidiar o aluno para que adquira os letramentos necessários à vida em sociedade. Para isso, os professores precisam não só se apropriar de embasamento teórico, aspecto este essencial para o ensino da língua materna (LM), mas abrir espaço para o trabalho que priorize os gêneros textuais orais formais públicos. Ao defendermos o trabalho com esses gêneros textuais em sala de aula, elegemos como objeto de ensino um dos gêneros mais utilizados tanto no contexto escolar, em diferentes componentes curriculares, quanto em outros contextos, o seminário. Dolz et al. (2011, p. 185), definem seminário como "[...] um gênero textual público, relativamente formal e específico, no qual um expositor especialista dirige-se a um auditório, de maneira (explicitamente) estruturada, para lhe transmitir informações, descrever-lhe ou lhe explicar alguma coisa."

Na concepção desses autores, é possível a construção de um objeto ensinável por meio da modelização didática, ou seja, da elaboração de uma ferramenta que apresente as dimensões ensináveis do gênero. Tomando por base esse modelo didático do gênero e objetivando a sua apropriação pelos alunos, sugerem que seja elaborada uma sequência didática, ou "conjunto de atividades escolares organizada, de maneira sistemática, em torno de um gênero textual oral ou escrito" (DOLZ; NOVERRAZ; SCHNEUWLY, 2011, p. 82). A partir de tais práticas, Dolz et al. (2011) chegam a um modelo didático do seminário, composto por três dimensões ensináveis: (1) a situação de comunicação, (2) a organização interna da exposição e (3) as características linguísticas. 
De acordo com Dolz et al. (2011, p. 185), o seminário "[...] é um discurso que se realiza numa situação de comunicação específica que poderíamos chamar de bipolar, reunindo o orador ou expositor e seu auditório." (1) Tem-se como locutor(es) um aluno, ou grupo de alunos, que assume $(\mathrm{m})$ o papel de expositor(es)-especialista(s) a respeito de um determinado tema. Seus interlocutores são alunos aos quais se dirige(m), que assumem o papel de auditório (poderá ser um grupo maior, caso, por exemplo, a exposição seja disponibilizada na internet, no rádio, na televisão etc.). Esse(s) aluno(s), em alguns momentos, assume $(\mathrm{m})$ o papel de professor, seja quando da apresentação, seja quando da avaliação da apresentação dos colegas.

A (2) finalidade do seminário é informar, esclarecer, transmitir um saber, ampliar o conhecimento do auditório a respeito de temas atuais ou de interesse da comunidade envolvida e/ou para a sociedade. Trata-se de um gênero textual pertencente à esfera escolar e/ou acadêmica. O (3) lugar de produção e circulação desse gênero textual é a sala de aula (ou outro local, como a sala de tecnologia educacional, por exemplo). Os suportes para a apresentação do seminário são, além da voz, resumos, fichas, esquemas, slides, computadores, datashow, microfone, etc.

No que diz respeito à (4) escolha do portador, os estudiosos genebrinos, ao discutirem e elencarem diferentes procedimentos que fazem parte do trabalho envolvendo a oralidade, ressaltam que uma didática que objetive desenvolver a expressão oral deve promover o conhecimento de "[...] diversas práticas orais de linguagem e as relações muito variáveis que estas mantêm com a escrita." (DOLZ; SCHNEUWLY; HALLER, 2011, p. 140). No caso do seminário, trata-se de um gênero textual oral vinculado com gêneros textuais escritos, em especial no planejamento da apresentação.

Já o (5) conteúdo a ser exposto no seminário pode abranger diversas temáticas, desde as escolares, passando pelas científicas, históricas e todas aquelas envolvendo os temas transversais ${ }^{7}$. Dolz, Noverraz e Schneuwly (2011) destacam a necessidade de os alunos conhecerem bem o que devem explicar em seus seminários, bem como a possibilidade de, eventualmente, já terem aprendido esses conteúdos em outras áreas de ensino (história, geografia, ciências etc.).

Em relação à segunda dimensão ensinável, a organização interna da exposição, Dolz et al. (2011) destacam um procedimento em duas partes. Primeiramente, deve haver a triagem de informações, a reorganização de elementos retidos e a hierarquização de ideias principais e secundárias. Tais informações, que devem preceder o planejamento textual, "[...] devem ser objeto de um trabalho em sala de aula, para que as exposições dos alunos não se reduzam a uma sequência de fragmentos temáticos sem ligação entre si." (DOLZ et al., 2011, p. 187). Nesse aspecto, é relevante destacar que os conteúdos contemplados para a apresentação devem ser mobilizados em sala de aula, seja mediante orientações para pesquisa extraclasse, com indicação de bibliografia, seja mediante a promoção de discussões ou debates.

\footnotetext{
${ }^{7}$ De acordo com o Ministério da Educação, trata-se de temas voltados à compreensão e à construção da realidade social e dos direitos e responsabilidades relacionados com a vida pessoal e coletiva e com a afirmação do princípio da participação política. Entre eles, pode-se citar ética, saúde, meio ambiente, orientação sexual, trabalho e consumo e pluralidade cultural.
} 
Por outro lado, entre os aspectos essenciais para o êxito em um seminário tem-se a forma como foi estruturada. Disso decorre a importância de ensinar aos alunos essa estrutura bem como a articulação entre suas diversas partes, pois se trata de um texto relativamente longo que eles precisam dominar. Assim, a segunda parte a ser observada na organização interna da exposição, de acordo com Dolz et al. (2011) é sua ordenação em sete fases: a de abertura; a de introdução ao tema; a de apresentação do plano da exposição; a de desenvolvimento e encadeamento dos diferentes temas; a de recapitulação e síntese; a de conclusão; e a de encerramento.

Já em relação à terceira dimensão ensinável do seminário, as características linguísticas, os pesquisadores genebrinos destacam que o trabalho didático "[...] deve fornecer ao aluno um repertório de forma que permitam (e necessitem) construir operações linguísticas (mais ou menos) específicas a esse gênero de texto." (DOLZ et al., 2011, p. 189). Os autores mencionam ainda quatro operações linguísticas que dizem respeito aos elementos do sistema textual desse gênero textual: (1) coesão temática, (2) sinalização do texto, (3) introdução de exemplos (explicativos ou ilustrativos) e (4) reformulações.

Dolz e Schneuwly, quando tratam especificamente do seminário, fazem referência à importância de elementos como a voz, o olhar e a atitude corporal quando elencam os objetivos gerais de um trabalho sobre esse gênero, mas não ampliam esse tema. Entretanto, quando tratam do oral como texto e da construção deste como objeto de ensino, referem-se ainda aos meios não linguísticos do oral. Em relação a esse aspecto, afirmam que "[...] a comunicação oral não se esgota somente na utilização de meios linguísticos ou prosódicos [...] mímicas faciais, posturas, olhares, a gestualidade do corpo ao longo da interação comunicativa vêm confirmar ou invalidar a codificação linguística e/ou prosódica e, mesmo, às vezes, substituí-la." (DOLZ; SCHNEUWLY; HALLER, 2011, p. 134).

Entre esses meios, os autores destacam os paralinguísticos (tom e volume da voz, ritmo da fala, pausa feitas durante a fala etc.), os cinestésicos (gestos, mímicas, movimentos corporais etc.), a posição do locutor (espaço ocupado, contato físico etc.), o aspecto exterior (roupas, penteado, óculos etc.) e a disposição dos lugares (iluminação, cadeiras, decoração etc.).

Assim, para Dolz et al. (2011, p. 193), o seminário é “[...] um objeto de ensino substancial e complexo, que solicita um número impressionante de conhecimentos práticos." Em vista disso, os autores sugerem que o gênero textual seja objeto de ensino em diferentes séries, destacando que o seu ensino contribui para a melhoria da competência linguístico-discursiva tanto no contexto escolar quanto no da vida social.

\section{OS GESTOS DIDÁTICOS: CENAS DA TRANSPOSIÇÃO DIDÁTICA INTERNA DO SEMINÁRIO}

Nesta seção focamos no processo de transposição didática interna, ou seja, na transformação do objeto de ensino em objeto ensinado. Apresentamos a seguir, para ilustrar a discussão teórica, parte da análise da SE em que a professora colaboradora 
(PCol) tratou de objetos de ensino relacionados à segunda dimensão ensinável do gênero textual seminário, a organização interna da exposição, quando trata especificamente da ordenação de suas partes e subpartes.

Neste dia, a PCol presentifica concretamente o gênero textual seminário em seu todo aos alunos e começa a decompô-lo a partir das perguntas que propõe para a sua análise. Inicialmente, apresenta a primeira atividade escolar. Para sua realização, a PCol mobiliza os GD de criação de dispositivos didáticos, concretizado no vídeo "Expressarse bem é fundamental para um bom profissional" (disponível em: $<$ https://www.youtube.com/watch?v=Bw1EfVUt0PE $>$ ), e o de formulação de tarefas, como se pode observar no excerto ${ }^{8}(1)$ :

(1) e... tem esse outro vídeo que vai falar sobre a expressão... então... eu quero que vocês prestem atenção... depois nós vamos comentar...

O vídeo traz uma reportagem que valoriza a expressão oral, destacando a capacidade de organizar bem as ideias e o saber falar em público, através da qual pretende suscitar o interesse dos alunos para o estudo do seminário e lhes possibilitar refletir sobre a importância de se expressar bem, tanto na exposição quanto na vida cotidiana. Foi uma estratégia importante da PCol para presentificação do gênero seminário, ou seja, o apontamento/elementarização de um aspecto relevante para a performance oral que será alvo de posterior comentário, o que serve também de incentivo para a produção desse gênero, que não é apenas didática.

Após a exibição do vídeo, através do GD específico de expor conteúdos, a PCol destaca que a dificuldade em relação à expressão e à timidez podem ser obstáculos na hora de apresentar um seminário, mas enfatiza que se trata de "uma questão de treinamento" e que a participação dos alunos em seminários os ajudaria a aperfeiçoar a capacidade de expressão e também a vencer a timidez. Destaca também que as aprendizagens sobre seminário deveriam ser aplicadas nas exposições solicitadas por professores de outros componentes curriculares, favorecendo o reconhecimento da relevância desse objeto de ensino.

Dando continuidade à aula, a PCol mobiliza novamente o GD de criação de dispositivos didáticos, agora concretizado pelo vídeo "10 Seminário Temático Matemática 2012" (Disponível em: <https://www.youtube.com/watch? $\mathrm{v}=$ adHvQsf8skM>), que possibilita a materialização do objeto de ensino seminário a partir de um modelo real de referência. Dolz, Noverraz e Schneuwly (2011, p. 89) apontam que as atividades escolares de observação e de análise de texto orais ou escritos, autênticos ou fabricados que evidenciam aspectos do funcionamento desses textos "[...] constituem o ponto de referência indispensável a toda aprendizagem eficaz da expressão." Além disso, a PCol distribui o formulário "Análise de um seminário modelo", contendo algumas questões norteadoras para a observação do

\footnotetext{
${ }^{8}$ Para as transcrições de trechos das videogravações, baseamo-nos nas convenções do Projeto da Norma Linguística Urbana Culta (NURC), iniciado em 1969, com o propósito de documentar e estudar a norma falada culta de cinco capitais brasileiras e ampliado em 1985, passando a abraçar aspectos como: análise da conversação, análise da narrativa, análise sócio-pragmática do discurso e outros.
} 
vídeo. Esse dispositivo didático apresenta questões que exploram conjuntamente algumas características do gênero seminário relativas às suas três dimensões ensináveis, enfatizando a segunda, a organização interna da exposição. Serve, nesse sentido, ao ajudar na construção das características do gênero, como preparação para a sua produção.

Neste momento da aula, entretanto, é possível observar que a PCol é reticente, durante a formulação de tarefas, ao apontar/elementarizar os aspectos do objeto de ensino que seriam alvo de posterior discussão, conforme destacamos no excerto (2):

\begin{abstract}
(2) ó::... através desse vídeo... vocês prestem atenção... ((alguns alunos fazem comentários)) é::... voltando... vou entregar pra vocês... um formulário que vocês vão prestar atenção... pra você observar... ((a PCol passa o material para um aluno))... procurem... é:.... um ou outro observar alguma coisa... mudança... o que que vocês acham que acontece no vídeo... o que nós passamos... já... passei no quadro pra vocês algumas coisas... do ( ) do que é certo... do que é errado e vamos discutir..
\end{abstract}

Embora a PCol tenha sido reticente ao ativar nos alunos conhecimentos acerca de objetos de ensino previamente trabalhados, não houve necessidade de reformular o comando. Isso porque, após a exibição do vídeo, ela busca ativar os conhecimentos anteriores dos alunos através de perguntas instigadoras de reflexão sobre os aspectos do objeto de ensino durante a exposição dialogada, um GD específico ligado à utilização da memória, conforme se observa no excerto (3):

(3) é::... quais são os exageros que não podemos cometer num seminário?... ((os alunos respondem)) nervoso... tinha alguém ali nervoso?... ((os alunos respondem)) aí começa a demonstrar com... gestos se você está nervoso ou não... ou no cabelo... na roupa... pé... geralmente fica... né?... qual o outro? ((a PCol continua questionando, os alunos respondem e ela comenta))

Esse gesto específico da PCol, de acordo com Nascimento e Brun (2016, no prelo), "[...] como ocorre na maioria das atividades feitas oralmente, implementa uma boa atmosfera na aula, dando chances à criação de espaços dialógicos entre os atores da sala de aula, [...]". As perguntas propostas visam à recuperação das aprendizagens consolidadas em aula anterior, quando utilizou um vídeo visando a apresentar dificuldades comuns do expositor. Esse gesto também leva à institucionalização do objeto, cuja intenção é a escolarização de saberes, e também favorece a mobilização do GD fundador de regulação local: por meio dos questionamentos, a PCol pode averiguar, por exemplo, se os alunos têm alguma dúvida sobre o objeto ensinado anteriormente.

No curso da aula, durante implantação de outro dispositivo didático, conduzida pelo GD de formulação de tarefas, ocorrem gestos específicos no métier docente, tais como o gesto de fazer colar o formulário no caderno e o de fazer responder por escrito às questões do formulário, como podemos observar no excerto (4):

(4) essa folha ((a PCol refere-se ao formulário “Análise de um seminário modelo)) eu quero colada no caderno... junto com a... as expressões... os erros que nós come... é::... que não se deve cometer ((aluna fala))... e vocês vão sentar agora em grupos e vão responder essas questões e nós vamos comentar elas oralmente... tá?... o importante é deixar no caderno que nós vamos utilizar depois... 
O gesto de regulação local destaca-se também neste momento da SE cujo objetivo é a produção e exposição do seminário, ou seja, a PCol quer identificar as apropriações dos alunos sobre esses aspectos tomando como base o vídeo anteriormente exibido. $\mathrm{O}$ GD específico de solicitar-lhes responder por escrito, no caderno, às perguntas do formulário revela uma mudança no dispositivo didático, até então as atividades escolares envolviam apenas respostas orais.

Durante a realização da tarefa, a PCol mobiliza o GD específico de fazer intervenções nos grupos, seja para responder a questionamentos dos alunos, seja para comentar itens específicos do formulário. Esse gesto da PCol é relevante, na medida em que essa mediação "individualizada" nos grupos, visando orientar o processo através de sugestões, alternativas, direcionamentos, possibilita apontar caminhos para os alunos trabalharem de forma autônoma, o que algumas vezes não se consegue através das intervenções coletivas. Entretanto, concordamos com Barros (2013, p. 255, grifos da autora), quando destaca que

\begin{abstract}
[...] as condições, de maneira geral, do nosso ensino público não são favoráveis a essas intervenções: classes numerosas; alunos indisciplinados; professor como único sujeito responsável pelas tarefas docentes de sala de aula (não há um assistente com quem ele possa dividir suas tarefas); falta de apoio pedagógico da coordenação da escola; excesso de conteúdo gramatical na progressão curricular (que condiciona, de forma consciente ou inconsciente, o trabalho do professor). Em condições melhores, talvez esse gesto didático começasse a ser mais mobilizado em sala de aula.
\end{abstract}

Tal gesto específico da PCol levou a outro, o de reformular o comando: em (4), observa-se que, ao formulá-lo, ela não esclarece para os alunos que devem responder às perguntas com base no seminário exibido no vídeo; em função disso, durante a realização da tarefa, ao observar que alguns a realizavam com base na exposição que estavam preparando, reportou-se ao grande grupo para reformulá-lo. Barros (2012, p. 116, grifos e comentários da autora), nesse sentido, afirma que os comandos caracterizam-se por: “a) explicitar a ação a ser executada (ler, grifar, comparar); b) citar os suportes que permitam a realização da tarefa ("o texto a seguir", "a figura X"); c) apresentar uma forma imperativa ("escreva", "comparar os dois textos"); [...]".

Embora esse gesto da PCol possa ter sido necessário em razão da falta de atenção dos alunos, chama a atenção para uma tarefa constitutiva da atividade docente, a de criar condições concretas para que os alunos realizem a atividade escolar.

$\mathrm{Na}$ sequência, entra em cena o GD específico de corrigir a atividade escolar, implementado por meio da leitura das respostas dadas pelos alunos. Tal gesto, além de favorecer o GD fundador de regulação, oportuniza outro GD específico da PCol, o de considerar as respostas dos alunos, total ou parcialmente. De acordo com Nascimento e Brun (2016, no prelo):

\footnotetext{
Aceitar as respostas, mesmo que parcialmente, valoriza o trabalho do aluno, eleva a autoestima e estimula a participação dele na aula. A ausência desses gestos - constitutiva do trabalho real do professor -, refletida na metodologia de correção, espelha a concepção de professor como o centro da aula, ou o detentor de todo o conhecimento e de todas as respostas, e não como mediador em uma relação dialógica com os alunos - sujeitos também do processo de ensino-aprendizagem -, que deveria ser marcada no gesto de corrigir a atividade.
} 
Durante a correção da atividade escolar, a PCol precisou mobilizar um GD específico controlador de indisciplina comum no espaço escolar: o de apelar à nota. Ou seja, na tentativa de controlar a classe agitada pela aproximação do final do período de aulas daquele dia, chamou a atenção dos alunos para o aviso de que a participação em aula também seria computada na avaliação relativa à tarefa final, a apresentação do seminário, contribuindo, dessa forma, para reforçar nos alunos a finalidade avaliativa para a produção do texto oral. Em função do encerramento das aulas, a correção teve continuidade e conclusão na aula seguinte, dia 27/8/15. Para isso, neste dia, a PCol retoma os questionamentos, como podemos verificar no excerto (5):

(5) vamos lá... nós paramos na questão dos participantes, os participantes dominam o assunto... eles leram?... eles falaram?... ((a PCol refere-se ao item "d" do formulário)) vamos voltar um pouco e relembrar... o que vocês lembram do vídeo? ((os alunos respondem às questões da $\mathrm{PCol})$ )

Ao dialogar com os alunos durante a correção, a PCol trata principalmente de aspectos da organização interna da exposição, cuja observação é sugerida por algumas perguntas do formulário (Análise de um seminário modelo). Além disso, o dispositivo didático traz perguntas sobre aspectos específicos da situação de comunicação do gênero e dos meios não linguísticos, o que permite à PCol articular objetos de ensino que ainda serão abordados em outros momentos da SE, um gesto relevante para conferir coerência e unidade ao processo de transposição didática interna do gênero textual seminário.

Em relação aos meios não linguísticos, por exemplo, a PCol menciona, ao comentar sobre o modo de se vestir dos expositores, ser importante o cuidado com o aspecto externo (DOLZ et al., 2011) em uma apresentação formal pública. Já em relação ao conteúdo, afirma ser fundamental para o sucesso da exposição em grupo que todos se apropriem do tema, para que não seja exposto de forma superficial ou fragmentada. Ou seja, o aluno deve dominar não apenas a "sua parte", mas o tema como um todo, para, no caso de alguém se esquecer de algo, outro componente do grupo possa auxiliá-lo.

\section{OS DADOS EMERGENTES NA TRANSPOSIÇÃO DIDÁTICA INTERNA DA SEGUNDA DIMENSÃO ENSINÁVEL DO GÊNERO SEMINÁRIO}

A fim de desenvolver a SE voltada ao estudo do seminário e preparação de uma exposição, várias ações foram realizadas pela PCol durante as 12 horas/aula. Neste artigo, apresentamos os GD que ela mobiliza durante a transposição didática interna relacionada a uma das três dimensões ensináveis desse gênero textual, a organização interna da exposição, mais especificamente, a ordenação de suas partes e subpartes.

Em relação a esses GD (fundadores e específicos) mobilizados pela PCol, primeiramente destacamos Oliveira (2013, p. 294). Com base em (AEBY-DAGHÉ; DOLZ, 2008), a autora afirma que para haver 
[...] efetivamente a aprendizagem (ainda que isso possa variar segundo os contextos de ensino), todos os gestos precisam ser implementados em sala de aula, porque, por meio deles, o aluno pode saber qual objeto está sendo focalizado, quais as dimensões tratadas, relacionar o que está aprendendo com o que já aprendeu, testar sua aprendizagem por meio de tarefas, avaliar o que ainda precisa ser apreendido e sintetizar as informações, relacionando-as com a utilidade de cada uma delas. Tudo isso feito a partir da/com a implementação de um dispositivo didático.

$\mathrm{Na}$ análise relativa a esses GD, os dados revelaram que, nas interações verbais durante a etapa da SE em questão, a PCol mobiliza os sete GD fundadores elencados no capítulo dedicado aos aspectos teóricos: presentificação, apontamento/elementarização, formulação de tarefas, criação de dispositivos didáticos, utilização da memória, regulação e institucionalização (BARROS, 2012), aos quais se interligam GD específicos.

Ao fazer isso, a PCol segue certa regularidade: a partir da criação de dispositivos didáticos e da formulação de tarefas, presentifica gênero textual seminário pelo apontamento/elementarização de objetos de ensino concernentes a sua segunda dimensão ensinável. Na sequência, mobiliza os demais GD fundadores: a utilização da memória, a regulação e a institucionalização.

Através do GD utilização da memória, um gesto fundador essencial para conexão entre os diferentes momentos da SE, a PCol possibilita não só a articulação de objetos de ensino a serem presentificados com os já trabalhados, mas também promove a institucionalização destes, a regulação do aprendizado em relação a eles e encaminha atividades escolares.

Quanto ao GD regulação, ocorre, na maioria das vezes, em função de outros GD que o implementaram concomitantemente. A PCol mobiliza-o através de GD específicos como os de fazer intervenções nos grupos durante a realização de tarefas, de fazer questionamentos orais durante a exposição dialogada e de corrigir a atividade escolar.

Já mediante o GD institucionalização, a PCol apresenta informações sobre o objeto de ensino seminário, conectando-o aos novos aspectos que deverão ser aprendidos pelos alunos relacionados à organização interna da exposição. Algumas vezes ocorre de forma dialogada, com a colaboração dos alunos; outras, concomitantemente à realização de tarefas, ou quando considera as respostas dos alunos em situação de correção de atividade escolar.

Esses GD fundadores colocam em evidência ainda outros GD específicos da PCol que se caracterizam, nas palavras de Nascimento e Brun (2016, no prelo), como "[...] gestos que demonstram o ajustamento à situação em sala de aula.", tais como o de fazer colar no caderno o dispositivo didático distribuído, o de fazer responder por escrito às questões (do formulário), o de fazer perguntas instigadoras, o de fazer intervenções nos grupos, o de reformular o comando, o de articular objetos de ensino e o de considerar as respostas dos alunos.

O gesto predominante, nesta etapa da SE, é o de expor os conteúdos, inclusive de forma dialogada, ou seja, a construção de objetos de ensino relacionados à segunda dimensão ensinável do seminário foi feita com base na exposição da PCol e diálogo com os alunos. Alguns dos GD específicos, entretanto, remetem a práticas coercitivas tradicionais, como o gesto de apelar à nota, com o objetivo de manter a disciplina em sala de aula. 
Neste trabalho, o foco foi o de analisar o processo de transposição didática interna do objeto de ensino seminário pelo viés dos GD fundadores e específicos mobilizados por uma professora durante o desenvolvimento de uma SE envolvendo esse gênero textual. Para isso, tomamos como base o referencial teórico-metodológico utilizado pelos estudiosos e pesquisadores da vertente genebrina de estudos dos gêneros e didática das línguas, sob a ótica do fazer docente como trabalho.

Cabe destacar que nossa intenção, ao descrever e analisar os GD fundadores e específicos mobilizados pela PCol não envolvia emitir julgamentos sobre a sua atuação, mas colaborar para uma maior inserção desses gestos nos debates que envolvem o trabalho docente. O foco foi o trabalho da PCol a partir desses gestos, que nos possibilitaram entender, durante o processo de transposição didática interna, a transformação do objeto de ensino seminário em objeto ensinado. Além disso, esses movimentos linguísticos permitiram compreender como a PCol realiza seu trabalho de ensinar.

Messias e Dolz (2015, p. 61) afirmam ser preciso que o professor tenha "[...] consciência do que, em suas escolhas, é facilitador ou não da aprendizagem, podendo rearticular ou modificar estratégias a fim de alcançar uma formação adequada aos aprendizes". A PCol afirmou que nem o seminário nem os demais gêneros textuais orais formais públicos compunham o rol de objetos de ensino alvo de suas intervenções pedagógicas. Assim, esta análise revelou que, a partir dos GD fundadores mobilizados por ela, emergiram GD específicos representativos de sua nova postura no trabalho com esse gênero textual.

Nascimento (2012) destaca que os GD representam um campo fecundo em termos de pesquisa envolvendo as representações e crenças dos docentes, em especial os de língua portuguesa a respeito de sua atividade. Concordamos com a autora sobre a relevância de se conhecer os GD e também com Dolz (2009, apud NASCIMENTO, 2011a, p. 423): "Considerando que o trabalho na sala de aula se constitui por movimentos discursivos e pragmáticos observáveis no desenvolvimento das atividades didáticas, a apropriação de gestos didáticos é fundamental para a formação de professores."

Por fim, a análise possibilitou, além de compreender a relevância desses movimentos discursivos que constituem o trabalho docente, reforçar a necessidade de acompanhamento pedagógico focalizado nas práticas didáticas docentes relacionadas aos gêneros textuais orais, em âmbito de formação inicial e continuada, sob a ótica desses GD.

\section{REFERÊNCIAS}

AEBY-DAGHÉ, S.; DOLZ, J. Des gestes didactiques fondateurs aux gestes spécifiques à l'enseignementapprentissage du texte d'opinion. In: BUCHETON, D.; DEZUTTER, O. (Org.). Le développement des gestes professionnels dans l'enseignement du français: un défi pour la recherche et la formation. Bruxelas: De Boeck, 2008, p. 81-105.

AMIGUES, R. Trabalho do professor e trabalho de ensino. In: MACHADO, A. R. (Org.) O ensino como trabalho: uma abordagem discursiva. Londrina-PR: Eduel, 2004, p. 35-53.

BARROS, E. M. D. Gestos de ensinar e de aprender gêneros textuais: a sequência didática como 
instrumento de mediação. 2012. 358 f. Tese (Doutorado em Estudos da Linguagem) - Centro de Letras e Ciências Humanas, Programa de Pós-Graduação em Estudos da Linguagem, Universidade Estadual de Londrina, Londrina, 2012.

. O trabalho do professor sob o ponto de vista dos gestos didáticos. Revista Brasileira de Linguística Aplicada [online]. 2013, v.13, n.3, p.741-769. Disponível em: $<$ http://www.scielo.br/scielo.php?script=sci_abstract\&pid=S198463982013000300004\&lng=en\&nrm=iso\&tlng=pt > Acesso em: 30 nov. 2016.

BRASIL. Ministério da Educação. Secretaria de Educação Fundamental. Parâmetros Curriculares Nacionais: Língua Portuguesa (terceiro e quarto ciclos). Brasília: MEC, 1998.

DOLZ, J. et al. A exposição oral. In: SCHNEUWLY, B.; DOLZ, J. et al. Gêneros orais e escritos na escola. Tradução e organização Roxane Rojo e Glaís Sales Cordeiro. 3. ed. Campinas: Mercado de Letras, 2011. p. 183-211.

DOLZ, J.; NOVERRAZ, M.; SCHNEUWLY, B. Sequências didáticas para o oral: apresentação de um procedimento. In: SCHNEUWLY, B.; DOLZ, J. et al. Gêneros orais e escritos na escola. Tradução e organização Roxane Rojo e Glaís Sales Cordeiro, 3. ed. Campinas: Mercado de Letras, 2011. p. 81-108. DOLZ, J.; SCHNEUWLY, B.; HALLER, S. O oral como texto: como construir um objeto de ensino. In: SCHNEUWLY, B.; DOLZ, J. et al. Gêneros orais e escritos na escola. Tradução e organização Roxane Rojo e Glaís Sales Cordeiro. 3. ed. Campinas: Mercado de Letras, 2011. p. 125-155.

FREITAS, P. R. de. Produção oral no seminário: possíveis apropriações em uma prática de ensino. 2016. 154 f. Dissertação (Mestrado em Linguística Aplicada) - Instituto de Estudos da Linguagem, Universidade Estadual de Campinas, Campinas, 2016.

LOPES, Q. V. O ensino do gênero exposição oral: um estudo de caso no $5^{\circ}$ ano do ensino fundamental. 2010. 112 f. Dissertação (Mestrado em Linguística) - Programa de Pós-graduação em Linguística, Universidade Federal da Paraíba, João Pessoa, 2010.

MACHADO, A. R.; BRONCKART, J-P. (Re-)configurações do trabalho do professor construídas nos e pelos textos: a perspectiva metodológica do grupo ALTER-LAEL. In: CRISTOVÃO, V. L.; ABREUTARDELLI, L. S. (Org.) Linguagem e educação: o trabalho do professor em uma nova perspectiva. Campinas: Mercado das Letras, 2009, p. 31-77.

MATO GROSSO DO SUL. Secretaria de Estado de Educação. Referencial

Curricular da Rede Estadual de Ensino do Mato Grosso do Sul: Ensino Fundamental. Mato Grosso do Sul: SEED, 2012.

MESSIAS, C.; DOLZ, J. As noções de gestos e de agir didático para a formação de professores de línguas: interfaces do trabalho docente. Cadernos Cenpec, São Paulo, v. 5, n. 1, p. 44-67, jan./jun. 2015. NASCIMENTO, E. L. A dupla semiotização dos objetos de ensino-aprendizagem: dos gestos didáticos fundadores aos gestos didáticos específicos. Signum: Estudos da Linguagem, Londrina, v. 14, n. 1, p. 421-445, jun. 2011a.

Mediações formativas e apropriação de gêneros textuais. SIMPÓSIO INTERNACIONAL DE GÊNEROS TEXTUAIS (SIGET), 6., Natal, RN. Anais... Natal: UFRN, 2011b. Disponível em: <http://www.cchla.ufrn.br/visiget/>. Acesso em: 22 jun. 2016.

Gestos de ensinar e de aprender: uma análise interacionista sociodiscursiva do trabalho em sala de aula. Revista Trama, v. 8, n. 16, p. 11-30, $2^{\circ}$ sem. 2012.

NASCIMENTO, E. L.; BRUN, E. P. Transposição didática e gestos profissionais de ensinar: a construção do objeto de ensino pelo professor de língua portuguesa. 2016 (no prelo).

OLIVEIRA, M. A. A. O ensino de língua portuguesa: usos do livro didático, objetos de ensino e gestos profissionais. 2013. 407 f. Tese (Doutorado em Linguística Aplicada) - Instituto de Estudos da Linguagem, Universidade Estadual de Campinas, Campinas/SP. 2013.

. Os gestos profissionais do professor e a construção dos objetos de ensino por meio do livro didático de língua portuguesa. SIMPÓSIO INTERNACIONAL DE ENSINO DE LÍNGUA PORTUGUESA (SIELP), 2., 2012, Uberlândia, MG. Anais... Uberlândia: EDUFU, 2012. Disponível em: <http://www.ileel.ufu.br/anaisdosielp/wp-content/uploads/2014/07/volume_2_artigo_199.pdf >. Acesso em: 15 abr. 2016.

SCHNEUWLY, B. Le travail enseignant. In: SCHNEUWLY, B.; DOLZ, J. Des objets enseiginés en classe de français. Rennes: Presses Universitaires de Rennes. 2009a. p. 29-45.

. L'objet enseigné. In: SCHNEUWLY, B.; DOLZ, J. Des objets enseignés en classe de français. Rennes: Presses Universitaires de Rennes, 2009b. p. 17-28. 
Recebido em: 25/09/17. Aprovado em: 29/07/18.

Title: The construction of the teaching object seminar under the point of view of didactic gestures teaching

Author: Mariza Perobelli

Abstract: This article examines how the teaching object seminar is transformed into object taught by the bias of didactic gestures, these understood as language instruments at the service of the teaching-learning process. The reflections are based on the theoreticalmethodological assumptions of Sociodiscursive Interactionism (SDI) and theoretical contributions derived from it. The research data were generated from the implementation of a teaching sequence in a class of $8^{\text {th }}$ grade of a public School (corresponding as Elementary School II in Brazil), by a teacher in the Dourados town - Mato Grosso do Sul State. Data analysis expanded the notion of didactic gestures and demonstrated the relevance of these language movements in praxis involving oral textual genres. It concludes by necessity of a pedagogical accompaniment focused on teaching didactic practices related to formal oral public oral genres, in the context of initial and continuing training, under the point of view of these didactic gestures.

Keywords: Oral textual genres. Teaching work. Didactic gestures.

Titulo: La construcción del objeto de enseñanza seminario bajo el punto de vista de los gestos didácticos

Autor: Mariza Perobelli

Resumen: Este artículo examina la manera como el objeto de enseñanza seminario es transformado en objeto enseñado por el sesgo de los gestos didácticos, entendidos como instrumentos de lenguaje al servicio del proceso de enseñanza-aprendizaje. Las reflexiones se fundamentan en los presupuestos teórico-metodológicos del Interaccionismo Sociodiscursivo (ISD) y aportes teóricos de él derivados. Los datos de la investigación fueron generados a partir de la implementación de una secuencia de enseñanza, en una clase de $8^{\circ}$ año de escuela primaria II, por una maestra de una escuela pública estatal de la ciudad de Dourados, Mato Grosso do Sul. El análisis de los datos amplió la noción de gestos didácticos y demostró la relevancia de esos movimientos lenguajeros en praxis involucrando géneros textuales orales. Se concluye por la necesidad de un acompañamiento pedagógico enfocado en las prácticas didácticas docentes relacionadas a los géneros textuales orales formales públicos, en ámbito de formación inicial y continuada, bajo la óptica de esos gestos didácticos.

Palabras clave: Géneros textuales orales. Trabajo docente. Gestos didácticos.

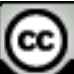

Este texto está licenciado com uma Licença Creative Commons Atribuição 4.0 Internacional. 